\title{
Novel Intervention in the Aging Population: A Primary Meningococcal Vaccine Inducing Protective IgM Responses in Middle-Aged Adults
}

\begin{abstract}
Marieke van der Heiden ${ }^{1,2 *}$, Annemieke M. H. Boots ${ }^{2}$, Axel A. Bonacic Marinovic', Lia G. H. de Rond', Marjan van Maurik', Irina Tcherniaeva', Guy A. M. Berbers ${ }^{1}$ and Anne-Marie Buisman ${ }^{1 *}$
\end{abstract}

OPEN ACCESS

Edited by:

Arnaud Marchant,

Free University of Brussels,

Belgium

Reviewed by: Geert Leroux-Roels,

Ghent University, Belgium Manish Sadarangani, University of British Columbia,

Canada

Mehmet Tevfik Dorak Liverpool Hope University, United Kingdom

*Correspondence:

Marieke van der Heiden marieke.van.der.heiden@rivm.nl;

Anne-Marie Buisman

annemarie.buisman@rivm.nl

Specialty section:

This article was submitted to Vaccines and Molecular

Therapeutics, a section of the journal Frontiers in Immunology

Received: 20 March 2017 Accepted: 27 June 2017

Published: 19 July 2017

Citation:

van der Heiden $M$, Boots $A M H$, Bonacic Marinovic AA, de Rond $L G H$,

van Maurik M, Tcherniaeva I,

Berbers GAM and Buisman A-M (2017) Novel Intervention in the Aging Population: A Primary Meningococcal Vaccine Inducing Protective IgM Responses in Middle-Aged Adults.

Front. Immunol. 8:817.

doi: 10.3389/fimmu.2017.00817
${ }^{1}$ Centre for Infectious Disease Control (Cib), National Institute for Public Health and the Environment (RIVM), Bilthoven, Netherlands, ${ }^{2}$ Department of Rheumatology and Clinical Immunology, University of Groningen, University Medical Centre Groningen, Groningen, Netherlands

Introduction: Vaccine responses are often reduced in the elderly, leaving part of the elderly population vulnerable to infectious diseases. Timely vaccination may offer a solution for strengthening memory immunity before reaching old age, which classifies middle-aged persons as a target age group for vaccine interventions. However, knowledge regarding the immunogenicity of primary immunizations in middle-aged adults is lacking. We determined the immunogenicity of a primary meningococcal vaccine towards which no or (very) low pre-vaccination immunity exists in middle-aged adults (NTR4636).

Methods: A vaccine containing multiple meningococcal groups (tetravalent) conjugated to tetanus toxoid (MenACWY-TT) was administered to middle-aged adults (50-65 years of age, $N=204$ ) in a phase IV single-center and open-label study. Blood samples were taken pre-, 7 days, 28 days, and 1 year post-vaccination. Functional antibody titers were measured with the serum bactericidal assay (SBA). Meningococcal- and tetanus-specific antibody responses were determined with a fluorescent bead-based multiplex immunoassay. A bi-exponential decay model was used to estimate long-term protection.

Results: In the majority of the participants, the meningococcal vaccine clearly induced naïve responses to meningococci W (MenW) and meningococci $Y$ (MenY) as compared to a booster response to meningococci C (MenC). After 28 days, 94, 99, and $97 \%$ of the participants possessed a protective SBA titer for MenC, MenW, and MenY, respectively, which was maintained in 76,94 , and $86 \% 1$ year post-vaccination. At this 1 -year time point, significantly lower SBA titers were found in participants without a pre-vaccination SBA titer. Overall, protective antibody titers were predicted to persist after 10 years in $40-60 \%$ of the participants. The SBA titers correlated well with the meningococcal-specific IgM responses, especially for MenW and MenY. Interestingly, these IgM responses were negatively correlated with age.

Conclusion: Primary immunization with a tetravalent meningococcal vaccine was highly immunogenic in middle-aged adults, inducing protective antibody titers in the vast 
majority of the participants lasting for at least 1 year. The age-related decrease in highly functional lgM responses argues in favor of vaccination against de novo antigens before reaching old age and, hence, middle-aged persons are an age group of interest for future vaccine interventions to protect the aging population.

Keywords: immunosenescence, aging, middle-aged, primary immunization, IgM, de novo antigens, meningococci

\section{INTRODUCTION}

The world population is rapidly aging. Worldwide predictions indicate that by the year 2050, the number of persons above 60 years of age is more than doubled as compared to 2015, with the numbers of persons above 80 years of age, the so-called "oldest-olds," increasing even faster (1). Population aging has major medical implications, as with age vulnerability to both chronic and infectious diseases increases. Due to increased numbers of susceptible elderly, the population herd immunity against infectious diseases may diminish $(2,3)$. Therefore, prevention of infectious diseases by immunization of the elderly is a prerequisite for establishing healthy aging $(4,5)$.

With age, reduced thymic output of naïve T-cells and reduced bone marrow B-cell niches are observed, causing compositional changes in both compartments of the adaptive immune system (5-8). These alterations affect both the cellular and the humoral immune responses to vaccines $(7,9)$. For example, the elderly show reduced T-cell responses after varicella zoster vaccination (10), as well as reduced functional antibody responses after seasonal influenza, pneumococcal, and yellow fever vaccination (11-15). Larger effects of immunological aging are expected for de novo immune responses, as compared with the above-mentioned recall responses (hereafter called booster responses), due to reduced numbers of naïve cells $(2,3,16)$.

Timely vaccination before reaching old age may offer a solution for circumventing these deleterious effects $(2,11)$. Due to the early appearance of the first signs of immune aging by the age of 50 (6), it has been suggested that immunization against new antigens most probably will have to be implemented at middle-age (2). However, the immunological fitness of middle-aged persons is largely unknown.

We determined the immunogenicity of a primary meningococcal vaccine in middle-aged adults (50-65 years of age). Due to herd immunity in the population after the mass vaccination campaign (in children 1-19 years of age) in 2002, circulation of meningococci $\mathrm{C}$ (MenC) is virtually non-existing, resulting in reduced memory immunity in the elderly population (17). Moreover, historical circulation of meningococci W (MenW) and meningococci Y (MenY) in the Netherlands has been very low, indicating that the meningococcal vaccination will most probably induce naïve type responses in older adults (17). Due to this expected low pre-vaccination immunity, the meningococcal vaccine was used as a model antigen to study primary vaccine responses in middle-aged adults.

Nowadays, next to young infants and adolescents, an increase of meningococcal cases is observed in persons over 65 years of age, which are mainly caused by MenW and MenY $(18,19)$. Also, the highest meningococcal case fatality rate has been reported in this age group, which may be due to underlying comorbidities (18-20). In addition, the currently ongoing MenW outbreak in the Netherlands is exactly following the course of the outbreak in the UK with 2 years delay, in which a large proportion of the invasive meningococcal disease cases was observed in persons above 65 years of age $(21,22)$. This vulnerability for meningococcal disease in the elderly population may further increase due to population aging $(17,23)$.

Until now, few studies investigated the immunogenicity of meningococcal vaccination in older adults $(23,24)$. In addition, immunogenicity studies were mostly performed in a historically naturally primed population. Here, we investigated the immunogenicity of a primary MenACWY-tetanus toxoid (TT) vaccination in an expected "immunologically naïve" middle-aged (50-65 years old) population. Moreover, a bi-exponential decay model was used to estimate the long-term protection induced by the vaccination in this middle-aged target group.

\section{MATERIALS AND METHODS}

\section{Study Design and Participants}

Within this phase IV single-center and open-label study, invitations were sent to middle-aged adults (between 50 and 65 years of age) in Amersfoort, a city in the middle of the Netherlands, during August/September 2014. The Dutch community-based administration was used to send the invitations. Potential participants were excluded based on the following criteria: antibiotic use or fever $\left(>38^{\circ} \mathrm{C}\right)$ within the last 14 days, serious diseases demanding immune suppressive medical treatment within the last 3 months, a known or suspected immune deficiency, a blood coagulation disorder, a neurologic disorder, administration of blood products in the past 6 months, serious surgery within the last 3 months, the use of hormone supplementation, pregnancy, a suspected allergy toward the vaccine components, history of serious adverse events after previous vaccinations, a previous meningococcal vaccination, a previous meningococcal episode, a tetanus vaccination within the last 5 years, and any vaccination in the month before enrollment. Written informed consent was obtained from all participants prior to enrollment and all procedures were in accordance with the Declaration of Helsinki. The medical ethical committee: Medical Research Ethics Committees United (MEC-U) approved the study and the study was registered at the Dutch trial register (NTR4636). 


\section{Vaccination and Blood Sampling}

A pre-vaccination blood sample was taken from all participants. Subsequently, all participants received the tetravalent meningococcal vaccine conjugated to TT (MenACWY-TT, Nimenrix, GlaxoSmithKline) by intramuscular administration. Blood samples were taken 7 days, 28 days, and 1 year post-vaccination. Serum samples were collected using serum clotting tubes (BD Biosciences) and were stored at $-20^{\circ} \mathrm{C}$ until further use. All participants were sampled during evening hours. In addition, all participants filled in a short health questionnaire during the first appointment.

\section{Serological Analysis}

$\operatorname{IgG}$ and IgG subclass concentrations specific for the polysaccharides of the meningococcal groups $\mathrm{C}, \mathrm{W}$, and $\mathrm{Y}$ (MenCWY), and TT were determined by the fluorescent-bead-basedmultiplex immuno assay as previously described (25-28). An internationally accepted TT-specific IgG concentration of $0.01 \mathrm{IU} / \mathrm{ml}$ was used as protection level (29). A similar method was used to determine the MenCWY-specific IgM concentrations, with the modification of using a donkey anti-human IgM RPE conjugate (Fc5 $\mu$ specific, Jackson ImmunoResearch).

MenA-specific measurements were left out of the analysis due to interference of varying levels of cross-reacting antibodies to MenA, present in these older age cohorts, in the immunoassay. Moreover, the analysis of MenCWY-specific responses is perceived sufficient to answer our primary research question in this study.

The MenCWY-specific protective antibody titers were determined with the serum bactericidal antibody assay using baby rabbit complement (rSBA) (Pelfreez, LOT\#13035EL), as described previously $(30,31)$. The MenC, MenW, and MenY strains used in the rSBA were C11, MP01240070, and S-1975, respectively, kindly donated by Prof. Dr. Ray Borrow from the Vaccine Evaluation Unit at Manchester (PHE). The bactericidal titer was expressed as the reciprocal of the highest serum dilution yielding $\geq 50 \%$ killing after $60 \mathrm{~min}$ of incubation. The internationally accepted correlate of protection used was an rSBA titer of $\geq 8$ for all groups, whereas a titer of $\geq 128$ was used as a more conservative measure for long-term protection $(31,32)$. Participants with an rSBA titer below detection level (rSBA seronegative) were assigned an rSBA titer of two for statistical purposes. A representative group of 100 persons was selected for the functional rSBA analysis, based on varying IgG levels from low to high concentrations, for all three meningococcal groups. For MenW and MenY, the same selection of participants was used. This selection had an overlap of 71 participants with the selection for MenC.

Gullsorb reagent human IgG (Meridian Biosciences ${ }^{\mathrm{TM}}$ ) was used for IgG depletion and goat-Anti-human IgM ( $\mu$-chain specific)-Agarose antibody beads (Sigma Aldrich) for IgM depletion in the serum samples.

\section{Statistics}

Normal distribution of the data was checked prior to each analysis and only cases with samples available at all time points were included in the analysis. Geometric mean concentrations
(GMCs) with 95\% confidence intervals [95\% CI] were calculated for the MenCWY-PS- and TT-specific IgG responses, as well as the MenCWY-PS-specific IgG subclass and IgM responses. MenCWY-PS-specific IgG and IgM concentrations were $\log$ transformed, after which the repeated measurements ANOVA was used to analyze the post-vaccination response. rSBA geometric mean titers (GMTs) with the corresponding $95 \%$ CI were calculated. Proportions and $95 \%$ CI of participants with an rSBA $\geq 8$ and $\geq 128$ were calculated with the Wilson/ Brown test. The proportion of participants with an rSBA $\geq 8$ and $\geq 128$ were compared between participants with and without a pre-vaccination serum bactericidal assay (SBA) titer with the Chi-squared test, whereas differences in GMTs were analyzed with the Mann-Whitney $U$ test. Differences in IgG ratios between the meningococcal groups were analyzed with the Mann-Whitney $U$ test preceded by the Kruskal-Wallis test and corrected for multiple comparisons with the Bonferroni correction.

Correlations between the rSBA titers and the IgG and IgM responses 28 days and 1 year post-vaccination were determined using the Spearman's rho correlation test. Graphpad Prism V7 and SPSS V22.0 were used for the statistical analysis. A $p$-value $<0.05$ was considered statistically significant.

\section{Bi-Exponential Decay Model}

To study the duration of protection, we used a Bayesian approach with a multilevel longitudinal model to statistically predict the dynamics of antibody concentrations (33). We performed Markov-chain Monte Carlo simulations to find the appropriate joint distribution of parameters which best could adjust the model to the measured rSBA titer datasets for MenC, MenW, and MenY. Assuming a simple exponential decay after reaching the time to peak $\left(t_{1}\right)$ would underestimate the persistence of protection (33-35). Therefore, we modeled the rSBA titer decay assuming that it follows a bi-exponential decay curve of the form:

$$
y\left(t>t_{1}\right)=y_{1}\left(e^{-\alpha_{1}\left(t-t_{1}\right)}+f e^{-\alpha_{2}\left(t-t_{1}\right)}\right) /(1+f)
$$

where $y_{1}$ is the peak antibody concentration level, $\alpha_{1}$ and $\alpha_{2}$ are the respective decay rates of each exponential component, and $f$ regulates the contribution of the exponential components.

The initial raise of antibody levels was assumed to be exponential until the time to peak $t_{1}$. Per individual, the three measured antibody levels were used to fit the multilevel model with their respective time point. The time to peak $\left(t_{1}\right)$ in the model was set to follow a lognormal distribution with a mean of 12 days (SD 8.5 days). The long-term antibody persistence was described using the decay curves predicted by the models. To assess the duration of protection, we focused on the predicted percentages of participants that possessed an rSBA titer $>8$ and $>128$, for any given time up to 10 years post-vaccination.

\section{RESULTS}

\section{Study Population}

A total of 204 middle-aged adults (mean age: 57.7 years; range 50-65 years; 52\% males) participated in the study (Figure 1). 


\section{Study outline}

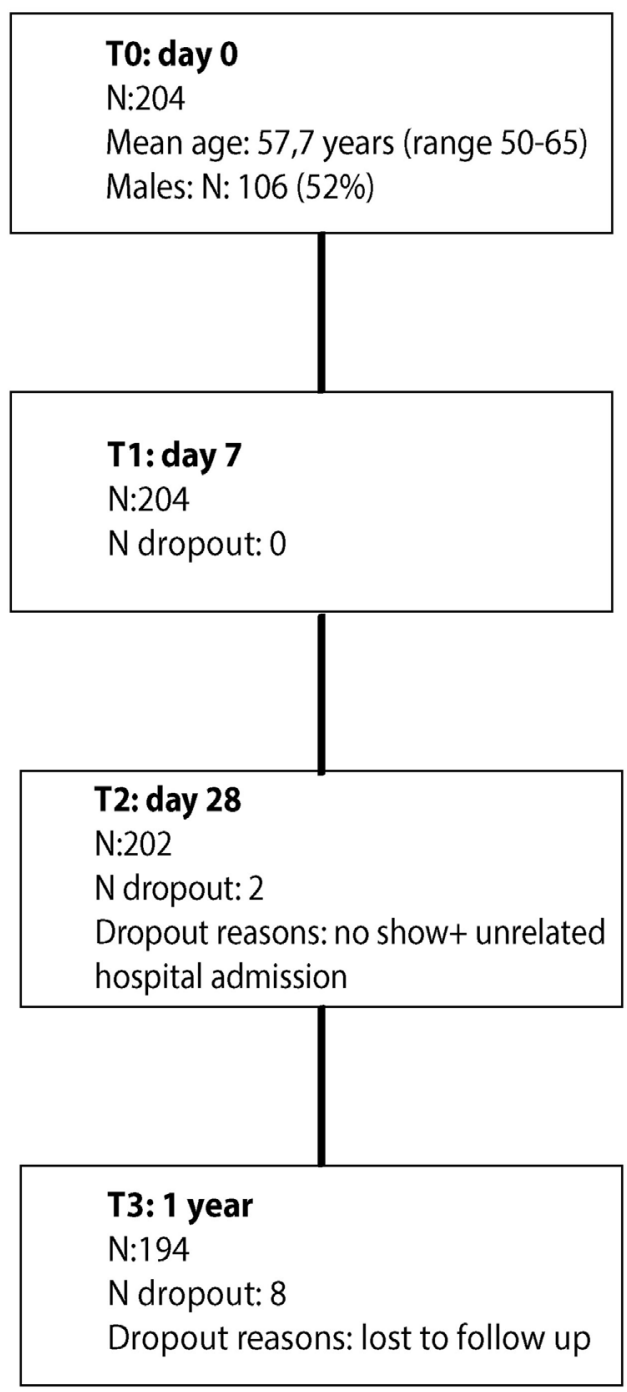

FIGURE 1 | Participant flow chart.

All participants received the MenACWY-TT vaccine. Overall, 194 participants $(95.1 \%)$ completed the study, with blood drawings before vaccination and at 7,28 days, and 1 year post-vaccination. Additional baseline participant characteristics are presented in Table S1 in Supplementary Material.

\section{IgG Responses Reflect General Naïve and Booster Responses after MenACWY-TT Vaccination in Middle-Aged Adults}

At first, longitudinal MenCWY and TT-specific IgG responses were investigated (Figures 2A-C; Figure S1 in Supplementary Material). Pre-vaccination, low IgG levels were observed for the different meningococcal groups. Seven days post-vaccination, IgG responses were enhanced for all three groups (Figures 2AC), although a higher increase in the IgG response (ratio day 7/pre) was observed for MenC as compared to MenW and MenY (Table 1). This was also reflected in the number of persons with an IgG fold increase above four at day 7, which was 58.8, 20.1, and 22.5\% for MenC, MenW, and MenY, respectively (Table 1). Moreover, compared to the other groups, a significant higher increase in MenC-specific IgG was observed 28 days post-vaccination (ratio day 28/pre) (Table 1). Taken together, these results are suggestive of a booster response to $\mathrm{MenC}$ as compared to a naïve response in the majority of the participants to MenW and MenY. Nonetheless, based on the IgG response 7 days post-vaccination, a few participants also showed booster responses for MenW and MenY as well as naïve responses to MenC. In addition, MenC-specific IgG concentrations showed a larger decay from 28 days to 1 year (ratio day 28/1 year) post-vaccination than seen for MenW and MenY IgG levels, resulting in comparable IgG GMCs 1 year post-vaccination for all three groups (Table 1). Notably, these IgG concentrations were still significantly enhanced compared with pre-vaccination levels (Figures $\mathbf{2 A - C}$ ). The TT conjugate clearly induced a booster response in the participants, since $71.6 \%$ of the persons showed highly significant increases in IgG concentrations 7 days post-vaccination (Table 1). In the majority of the middle-aged persons, pre-vaccination TT-specific IgG concentrations were above the protection level of $0.01 \mathrm{IU} / \mathrm{ml}$ and these were significantly enhanced up to 1 year postvaccination (Table 1; Figure S1 in Supplementary Material). Within this cohort, we did not observe any effects of age, gender, and CMV seropositivity on the IgG responses (Table S2 in Supplementary Material).

Remarkably, a robust IgM response was observed for all meningococcal groups and these IgM levels were still enhanced 1 year post-vaccination (Figures 2D-F). A significant negative correlation was found between the IgM responses and age for MenC and MenW, whereas a negative trend was observed for MenY (Table 2). However, the low predictive value of the model $\left(\mathrm{R}^{2}\right.$ model) indicates that age and pre-existing IgM concentrations were not the major factors predicting the IgM concentrations post-vaccination.

\section{The Meningococcal Groups Induced Protective rSBA Responses in Middle-Aged Adults}

A representative group of 100 persons was selected for the functional rSBA analysis, based on the $\operatorname{IgG}$ concentrations. As expected, the majority of the participants possessed prevaccination rSBA titers below the internationally accepted protection level of 8 . MenC, MenW, and MenY-specific prevaccination rSBA titers $\geq 8$ were observed in 18,23 , and $27 \%$ of the middle-aged participants (Table 3). Moreover, 28 days post-vaccination, the vast majority of the participants possessed an rSBA titer $\geq 8$, which was 94,99 , and $97 \%$ for MenC, MenW, and MenY, respectively. In addition, 92, 97, and 95\% for MenC, MenW, and MenY, respectively, possessed an rSBA titer $\geq 128$, the cutoff titer used for long-term protection (Table 3). One-year post-vaccination, protective antibody titers were still found in $76-94 \%$ of the participants (Table 3). Surprisingly, at this time 


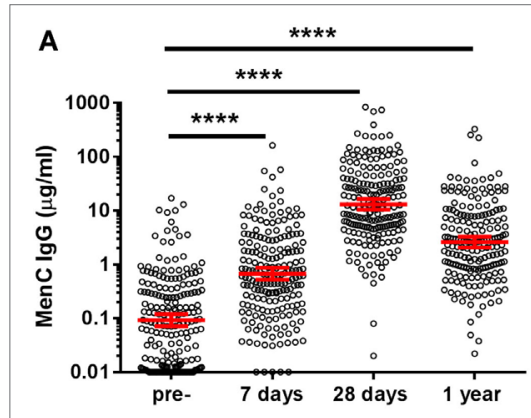

D

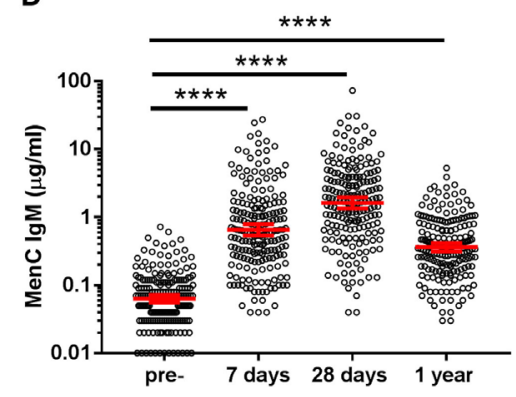

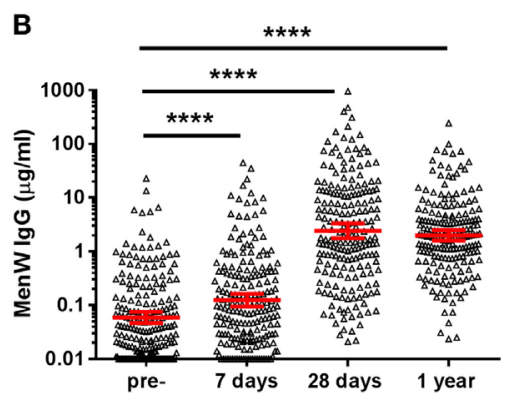

$\mathbf{C}$

E

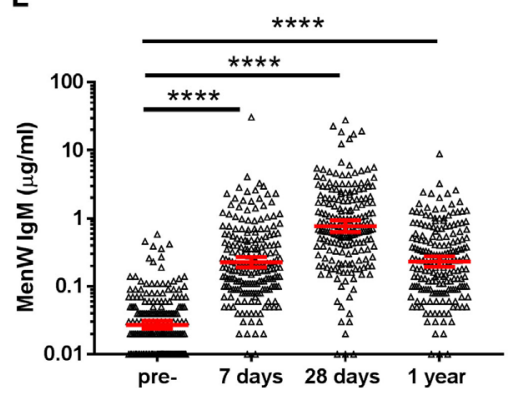

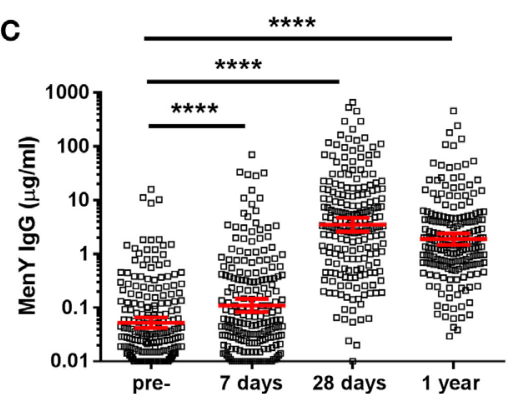

$\mathbf{F}$

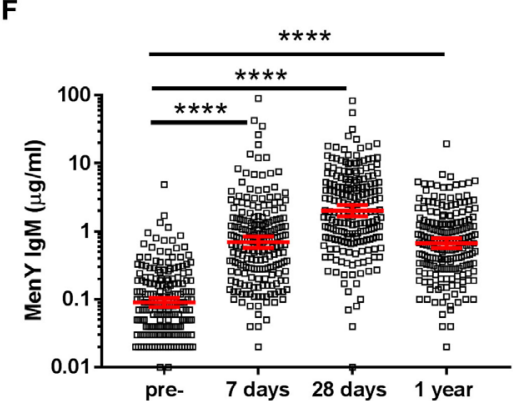

FIGURE 2 | MenCWY-specific IgG and IgM responses. MenC (A), MenW (B), MenY (C) polysaccharide-specific IgG, and MenC (D), MenW (E), MenY (F) polysaccharide-specific lgM responses pre- and post-vaccination. The lines indicate the geometric mean concentrations with $95 \% \mathrm{Cl}$ intervals. The different time points were compared with the repeated measured ANOVA, which was highly significant for all comparisons $(p<0.0001)$, after which pairwise comparisons between the time points were performed.

TABLE 1 | MenCWY and tetanus toxoid (TT)-specific lgG responses.

\begin{tabular}{|c|c|c|c|c|}
\hline & MenC $(\mu \mathrm{g} / \mathrm{ml})$ & MenW ( $\mu \mathrm{g} / \mathrm{ml})$ & MenY $(\mu \mathrm{g} / \mathrm{ml})$ & TT (IU/ml) \\
\hline Day 7 GMC [95\% Cl] & $0.67[0.52-0.86]$ & $0.13[0.09-0.16]$ & $0.11[0.08-0.14]$ & $6.81[5.84-7.94]$ \\
\hline Number of fold change $>4(\%)$ & $120(58.8 \%)$ & $41(20.1 \%)^{\star \star \star \star, a}$ & $46(22.5 \%)^{\star \star \star \star, a}$ & $146(71.6 \%)$ \\
\hline Day 28 GMC [95\% Cl] & 13.03 [10.39-16.35] & $2.43[1.78-3.33]$ & $3.49[2.59-4.71]$ & $13.89[11.71-16.48]$ \\
\hline Ratio day 28/1 year [95\% Cl] & $5.0[4.4-5.6]$ & $1.3[1.1-1.5]^{\star \star \star \star, a}$ & $1.8[1.6-2.2]^{\star \star \star \star, a}$ & $3.9[3.5-4.3]$ \\
\hline
\end{tabular}

The MenC, MenW, and MenY polysaccharide and TT-specific geometric mean concentrations (GMCs [95\% Cl], in microgram per milliliter) at the different time points pre- and postvaccination. Moreover, ratios between day 7/pre, day 28/pre, day 28/1 year, and the number of persons with an IgG fold change above four at day 7 are indicated for the different groups.

${ }^{*} p<0.05,{ }^{* *} p<0.01,{ }^{* * * *} p<0.0001$.

aCompared to MenC.

${ }^{b}$ Compared to MenY.

The MenC, MenW, and MenY-specific ratios at day 7, 28, and 1 year were compared with the Mann-Whitney $U$ test after correction for multiple testing. Moreover, the numbers of persons with a fold change $>4$ at day 7 were compared with the Chi-square test.

point, slightly higher rSBA titers were observed for MenW and MenY compared with MenC. Moreover, a small, but significant negative correlation of the rSBA titer was found with age; 28 days post-vaccination for MenC (rho: $-0.239, p: 0.017)$ and 1 year post-vaccination for MenW (rho: $-0.300, p: 0.002$ ) (Table S3 in Supplementary Material). No gender differences were observed (data not shown).

\section{Modeling of the Protection Levels 10 Years Post-Vaccination}

Using a bi-exponential decay model, the proportion of participants with rSBA titers above the protective cutoff level of 8 at 10 years post-vaccination was estimated to be around 40,40 , and $60 \%$ for MenC, MenW, and MenY, respectively (Figures S2A-C in Supplementary Material). Moreover, 20, 20, and 40\% of the 
participants were expected to possess rSBA titers above the protective cutofflevel of 128 at 10 years post-vaccination for MenC, MenW, MenY, respectively (Figures S2D-F in Supplementary Material).

\section{Differences in rSBA Response between Participants with and without Pre- Vaccination rSBA Titers}

In one-fourth of the participants, a detectable pre-vaccination rSBA titer $(\mathrm{rSBA} \geq 4)$ was observed (Figures 3A-C). Subsequently,

TABLE 2 | Effect of age and gender on the MenCWY IgM responses.

\begin{tabular}{|c|c|c|c|c|c|}
\hline Group & Timepoint & $\begin{array}{l}\text { Predicting } \\
\text { variable }\end{array}$ & $p$-Value & $\beta$ coefficient & $\begin{array}{c}R^{2} \\
\text { mode }\end{array}$ \\
\hline \multirow[t]{9}{*}{ MenC } & 7 days & Pre-IgM & 0.002 & 0.218 & 0.102 \\
\hline & & Age & 0.001 & -0.237 & \\
\hline & & Gender & 0.740 & -0.022 & \\
\hline & 28 days & Pre-IgM & 0.046 & 0.142 & 0.048 \\
\hline & & Age & 0.018 & -0.168 & \\
\hline & & Gender & 0.158 & -0.100 & \\
\hline & 1 year & Pre-IgM & 0.000 & 0.292 & 0.106 \\
\hline & & Age & 0.024 & -0.158 & \\
\hline & & Gender & 0.426 & -0.055 & \\
\hline \multirow[t]{9}{*}{ MenW } & 7 days & Pre-IgM & 0.000 & 0.246 & 0.154 \\
\hline & & Age & 0.000 & -0.315 & \\
\hline & & Gender & 0.326 & -0.066 & \\
\hline & 28 days & Pre-IgM & 0.111 & 0.115 & 0.055 \\
\hline & & Age & 0.002 & -0.215 & \\
\hline & & Gender & 0.256 & -0.081 & \\
\hline & 1 year & Pre-IgM & 0.000 & 0.307 & 0.148 \\
\hline & & Age & 0.010 & -0.176 & \\
\hline & & Gender & 0.045 & -0.139 & \\
\hline \multirow[t]{9}{*}{ MenY } & 7 days & Pre-IgM & 0.001 & 0.238 & 0.090 \\
\hline & & Age & 0.019 & -0.161 & \\
\hline & & Gender & 0.074 & -0.123 & \\
\hline & 28 days & Pre-lgM & 0.554 & 0.043 & 0.030 \\
\hline & & Age & 0.037 & -0.148 & \\
\hline & & Gender & 0.067 & -0.131 & \\
\hline & 1 year & Pre-IgM & 0.000 & 0.272 & 0.100 \\
\hline & & Age & 0.108 & -0.113 & \\
\hline & & Gender & 0.049 & -0.139 & \\
\hline
\end{tabular}

Linear regression was performed using the log-transformed lgM concentrations. Age was included as a continuous variable. Gender: $0=$ female, $1=$ male. The effects of age and gender were adjusted for the presence of pre-vaccination immunity (Pre-lgM), since pre-lgM was perceived a confounder. After correction for multiple testing, a p-value $<0.05 / 9=0.006$ was considered significant. Significant correlations are indicated in bold. we compared the vaccine response between participants being seropositive $(\mathrm{rSBA} \geq 4)$ or being seronegative at the pre-vaccination time point (Figure 3; Table S4 in Supplementary Material). Similar rSBA titers were observed in both groups 28 days postvaccination for all meningococcal groups (Figures 3A-C; Table S4 in Supplementary Material), indicating a robust increase in rSBA titer in the seronegative participants. At day 28, 89.9, 96.1, and 93.2\% of the seronegative participants showed an rSBA titer $\geq 128$ for MenC, MenW, and MenY, respectively, compared with $100 \%$ of the seropositive participants (Figures 3D-F; Table S4 in Supplementary Material). One-year post-vaccination, rSBA titers showed a significantly higher decay in the seronegative participants, reaching significance for MenW and MenY, and resulting in rSBA titers below the protection limit $(\mathrm{rSBA} \geq 8)$ in some participants (Figure 3; Table S4 in Supplementary Material).

\section{Strong Correlations between the MenW- and MenY-Specific IgM Responses and Antibody Functionality}

Since the rSBA titers and IgG responses for the different groups did not show a similar pattern, the correlations between the IgG and rSBA responses for the three meningococcal groups were determined (Figures $\mathbf{4 A - C}$ ). A moderate correlation was found for MenC (28 days: rho 0.561, $p<0.001,1$ year: rho 0.548 , $p<0.001$ ) (Figure 4A), whereas the correlations for MenW (28 days: rho 0.356, $p<0.001,1$ year: rho 0.307, $p<0.002$ ) and MenY (28 days: rho $0.201, p=0.045,1$ year: rho $0.214, p=0.033$ ) were rather low (Figures $4 \mathrm{~B}, \mathrm{C}$ ).

This encouraged us to investigate whether MenC-, MenW-, and MenY-specific IgM responses could explain this low correlation. Remarkably, a good correlation was found between the rSBA titers and the IgM responses for both MenW (28 days: rho 0.687, $p<0.001$, 1 year: rho $0.761, p<0.001)$ and MenY (28 days: rho 0.690, $p<0.001$, 1 year: rho 0.729, $p<0.001$ ) (Figures 4E,F), whereas a moderate correlation was found for MenC (28 days: rho $0.594, p<0.001,1$ year: rho 0.529, $p<0.001$ ) (Figure 4D). In order to confirm the important contribution of the IgM antibodies to the rSBA response, IgG was depleted in a subset of the samples varying in SBA titer (Figures S3A,C in Supplementary Material). MenW and MenY rSBA titers remained almost equal after IgG removal. By contrast, these rSBA titers were largely reduced after IgM

TABLE 3 | MenCWY-specific serum bactericidal antibody responses using baby rabbit complement (rSBA).

\begin{tabular}{|c|c|c|c|c|}
\hline Time point & Value & MenC & MenW & MenY \\
\hline Pre- & $\begin{array}{l}\text { GMT } \\
\geq 8 \% \\
\geq 128 \%\end{array}$ & $\begin{array}{c}3.9[2.9-5.3] \\
18[11.7-26.7] \\
7[3.4-13.8]\end{array}$ & $\begin{array}{c}5.4[3.8-7.9] \\
23[15.8-32.2] \\
8[4.1-15.0]\end{array}$ & $\begin{array}{l}6.9[4.5-10.4] \\
27[19.3-36.4] \\
17[10.9-25.5]\end{array}$ \\
\hline 28 days & $\begin{array}{l}\text { GMT } \\
\geq 8 \% \\
\geq 128 \%\end{array}$ & $\begin{array}{c}1,469[950.5-2,269] \\
94[87.5-97.2] \\
92[85.0-95.9]\end{array}$ & $\begin{array}{c}1,771[1,354-2,315] \\
99[94.6-100] \\
97[91.5-99.2]\end{array}$ & $\begin{array}{c}1,448[1,026-2,044] \\
97[91.5-99.2] \\
95[88.8-97.8]\end{array}$ \\
\hline 1 year & $\begin{array}{l}\text { GMT } \\
\geq 8 \% \\
\geq 128 \%\end{array}$ & $\begin{array}{c}111.4[66.6-186.4] \\
76[66.8-83.3] \\
61[51.2-70]\end{array}$ & $\begin{array}{c}335.5[236.9-475.1] \\
94[87.5-97.2] \\
74[64.6-81.6]\end{array}$ & $\begin{array}{c}247.3[158.1-386.7] \\
86[77.9-91.5] \\
79[70.0-85.8]\end{array}$ \\
\hline
\end{tabular}

MenCWY-specific GMTs are presented with the [95\% Cl]. The percentages and

[95\% Cl] of participants with an rSBA titers above 8 (cutoff for protection) and 128 (cutoff for long-term protection) are given at all time points.

GMT, Geometric mean titer. 

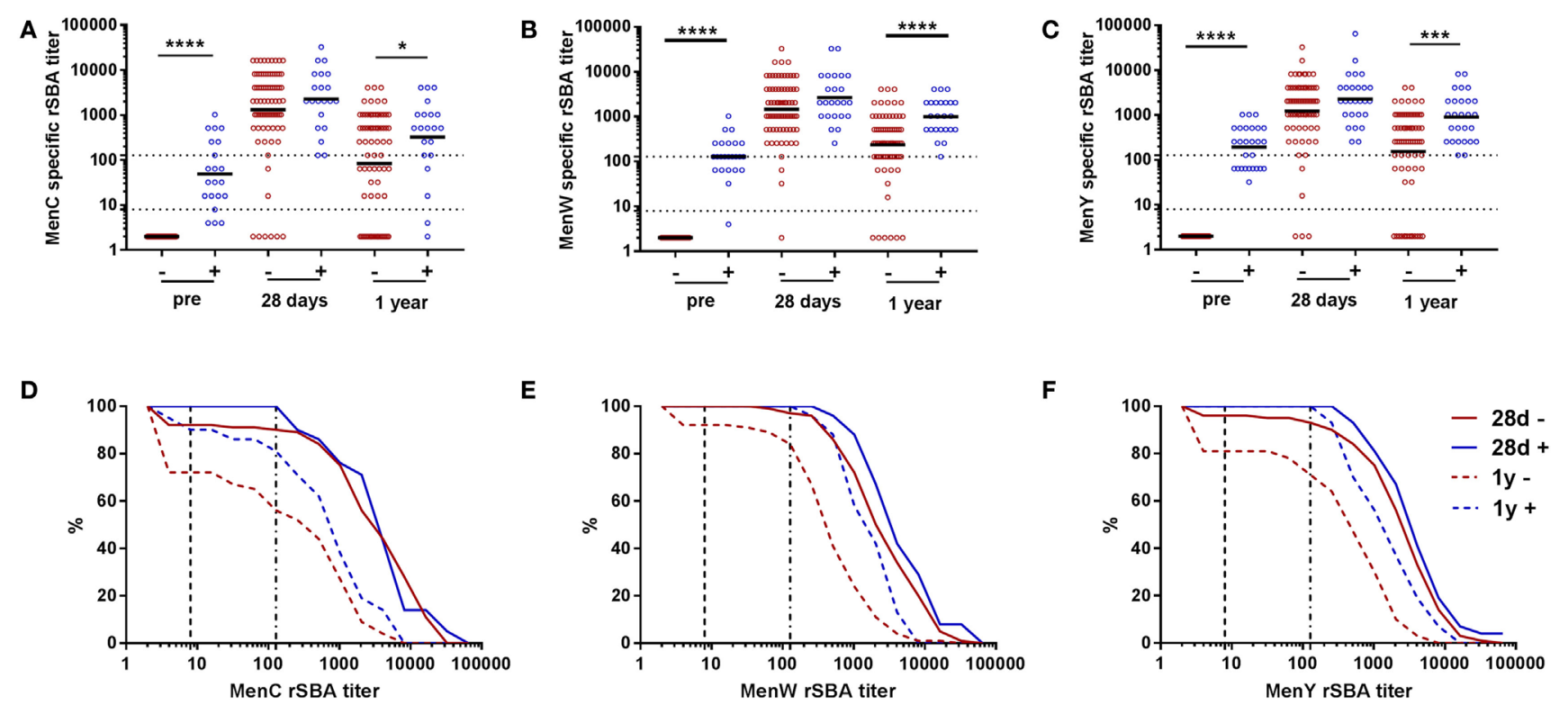

FIGURE 3 | MenCWY serum bactericidal antibody responses in participants with and without pre-vaccination rSBA titers. MenC (A), MenW (B), and MenY (C) specific rSBA responses at the different time points for pre-vaccination seronegative (-, red) and seropositive (+, blue) participants. The geometric mean titers are indicated. The seronegative and seropositive participants were compared at the different time points using the Mann-Whitney $U$ test ${ }^{\star} p<0.05$, ${ }^{\star \star \star} p<0.001$, and ${ }^{\star \star \star \star} p<0.0001$. Reverse cumulative distribution graphs at day 28 and 1 year post-vaccination for MenC (D), MenW (E), and MenY (F) separated for the pre-vaccination seronegative (red) and seropositive (blue) participants.

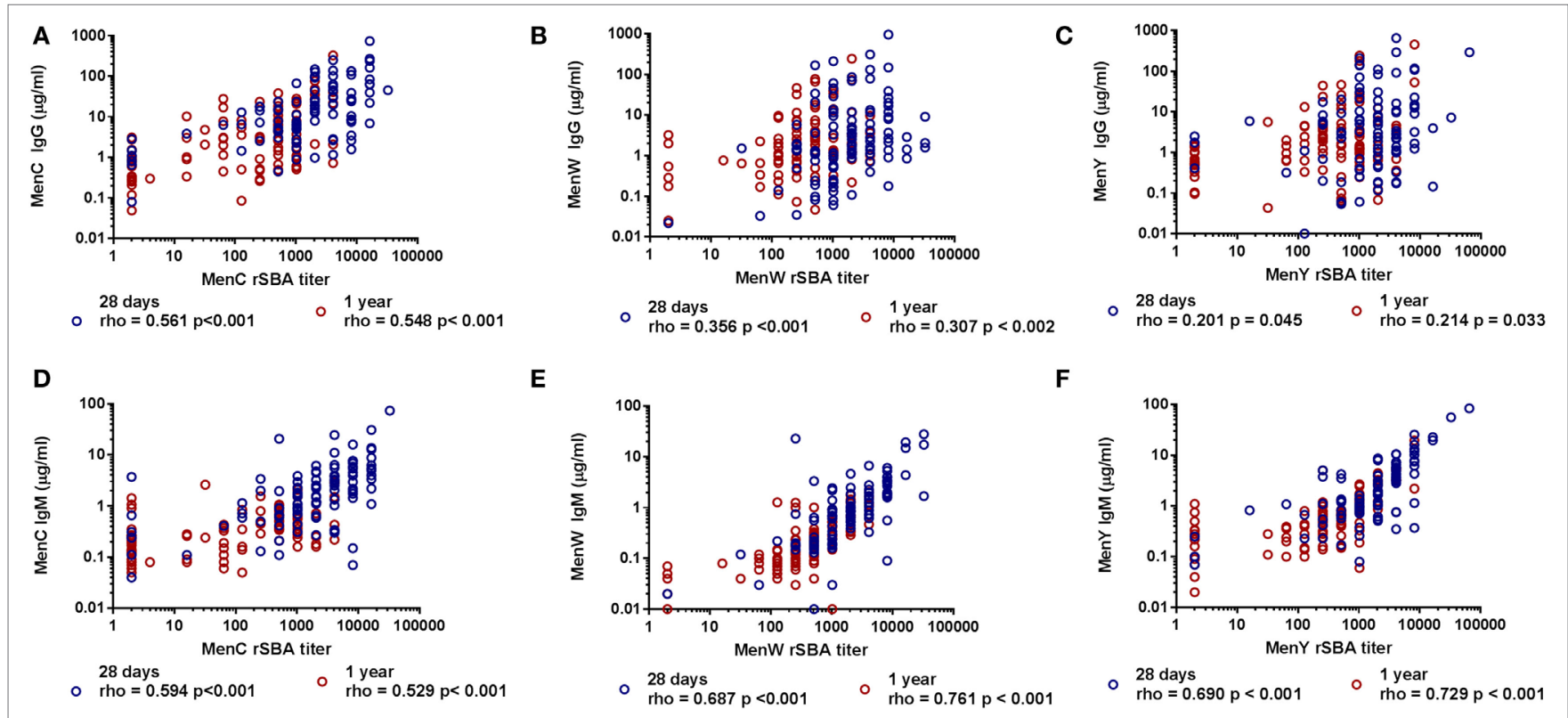

FIGURE 4 | Correlation between the MenCWY-specific IgG and IgM responses with the serum bactericidal antibody responses. The correlation between the MenC (A), MenW (B), and MenY (C) PS-specific IgG responses and the MenC (D), MenW (E), and MenY (F) PS-specific IgM responses with the rSBA responses at 28 days and 1 year post-vaccination. Correlations were determined with the Spearman's rho correlation test.

depletion (Figures S3B,D in Supplementary Material), although the rSBA titer was mostly retained in participants with very high IgG concentrations. The data suggest that the protective rSBA titers are mediated via induction of IgM type antibodies, mainly for MenW and MenY.

\section{Differential Meningococcal Group-Specific IgG Subclass Responses}

Finally, we investigated whether IgG subclass responses differed between the naive (MenW and MenY) and booster (MenC) 
TABLE 4 | MenCWY-specific IgG subclass responses.

\begin{tabular}{|c|c|c|c|c|}
\hline Timepoint & Measurement & MenC $(\mu \mathrm{g} / \mathrm{ml})$ & MenW ( $\mu \mathrm{g} / \mathrm{ml})$ & MenY $(\mu \mathrm{g} / \mathrm{ml})$ \\
\hline \multirow[t]{3}{*}{28 days } & $\operatorname{lgG} 1[95 \% \mathrm{Cl}]$ & 3.1 [2.53-3.85] & 0.4 [0.30-0.52] & $2.3[1.80-2.83]$ \\
\hline & $\operatorname{lgG} 2[95 \% \mathrm{Cl}]$ & $5.1[3.84-6.67]^{\star \star \star, a}$ & $0.7[0.49-1.03]^{\star \star \star, a}$ & $1.4[0.97-1.92]^{\star \star, a}$ \\
\hline & lgG1/lgG2 ratio [95\% Cl] & $0.6[0.48-0.81]$ & $0.6[0.40-0.76]$ & $1.6[1.19-2.21]$ \\
\hline \multirow[t]{3}{*}{1 year } & $\operatorname{lgG} 1[95 \% \mathrm{Cl}]$ & $1.0[0.82-1.16]$ & $0.6[0.40-0.76]$ & 1.6 [1.30-1.98] \\
\hline & $\operatorname{lgG} 2[95 \% \mathrm{Cl}]$ & $1.2[0.85-1.47]$ & $0.8[0.63-1.11]^{\star \star, b}$ & $0.8[0.62-1.13]^{\star * \star, b}$ \\
\hline & lgG1/lgG2 ratio [95\% Cl] & $0.8[0.65-1.10]$ & 0.7 [0.50-0.87] & $1.9[1.41-2.51]$ \\
\hline
\end{tabular}

Geometric mean concentrations [95\% Cl] are indicated. Meningococcal group-specific lgG1 and lgG2 responses at the different time points were compared with the

Mann-Whitney $U$ test.

${ }^{* *} p<0.01,{ }^{* * *} p<0.001$.

algG2 vs $\lg G 1$ at day 28.

b/gG2 vs IgG1 at 1 year.

responses at middle-age, as IgG subclass responses have previously been shown to affect the antibody functionality. IgG subclass responses were highly variable for all three groups. A slightly skewed IgG2 response was observed for MenC and MenW, whereas the response to MenY showed IgG1 skewing, as shown by the IgG1/IgG2 ratio (Table 4). Besides a primarily MenCspecific IgG2 skewed response, 1 year post-vaccination IgG1 and IgG 2 contributed equally to the IgG response, suggesting a more rapid decay of IgG2 than IgG1 over time (Table 4), which was not seen for the IgG2 skewed MenW response. Also, the IgG1 skewed response to MenY remained stable.

\section{DISCUSSION}

In this study, we demonstrate that a primary tetravalent meningococcal vaccine conjugated to TT (MenACWY-TT) in middle-aged adults is highly immunogenic. The vast majority (94-99\%) of the participants developed protective antibody titers against three meningococcal groups 1 month post-vaccination. Moreover, 1 year post-vaccination protective antibody titers were still found in $76-94 \%$ of the participants. This level of protection was slightly lower in participants without detectable pre-vaccination rSBA titers compared with participants with pre-vaccination rSBA titers. Overall, in about $40-60 \%$ of the participants protective antibody titers are predicted to last for 10 years post-vaccination. Of importance, the protective rSBA titers were strongly associated with the meningococcal group-specific IgM responses, especially for MenW and MenY. Remarkably, these IgM responses were still enhanced 1-year post-vaccination and declined with advancing age even in this middle-aged (50-65 years) group.

Since our study is one of the few evaluating the immunogenicity of the MenACWY-TT vaccine in older adults, comparative data are scarce. We observed similar proportions of participants with protective post-vaccination titers (rSBA > 128) 1 month postvaccination as reported by a study evaluating the immunogenicity of the MenACWY-TT vaccination in persons 56-103 years of age, of which $67 \%$ was middle-aged (56-65), in Lebanon (23). The Lebanese population, however, has a different epidemiological background than the Dutch population, since high meningococcal pre-vaccination levels were found in most Lebanese adults (23). Despite these differences in pre-vaccination immunity, comparable short-term vaccine responses were observed. In addition, two studies in the USA reported the immunogenicity of a pneumococcal conjugate vaccine with a similar composition of conjugated polysaccharides (the PCV13 vaccine), in older adults (50-69 years of age) 1 year post-vaccination $(36,37)$. However, since a large part of the older adult populations is likely to be primed naturally for the majority of the pneumococcal groups, these vaccines induced a booster response. In our study, a large induction of MenC-specific IgG concentrations 7 days post-vaccination was indicative of a booster response for MenC in most participants $(38,39)$. Since this meningococcal group induced robust functional antibody responses as measured by the SBA in our study adults, we confirmed the immunogenicity of a booster vaccine in middle-aged adults. In addition, we demonstrated robust antibody responses against the groups MenW and MenY, which showed a more de novo immune response in the majority of the middle-aged adults.

The observations of booster responses for MenC in the majority of the middle-aged adults, and the more naïve responses for MenW and MenY are in agreement with the meningococcal circulation in the Dutch population in the past (17). The MenCspecific booster response suggests long-term persistence of MenC-specific IgG-based memory immunity in adults, since the circulation of MenC was nearly eradicated after the mass vaccination campaign of 2002 (40). These memory cells may reside in the bone marrow and do not necessarily correlate with serum antibody levels $(41,42)$. The currently ongoing circulation of MenW and MenY might explain the high pre-vaccination SBA titers and IgM concentrations that were found in a small part of the participants, suggesting prior exposure $(18,21)$. However, meningococcal carriage studies in older adults are lacking to confirm our results.

We observed highly variable IgG subclass responses in the middle-aged adults for all meningococcal groups, a common finding after conjugate-carrier vaccination in adults (43-45). This may be explained by multifactorial causes such as hostspecific contacts during life, chemical antigen characteristics as well as the age of the vaccinees $(45,46)$. Clearly, this would require further study. In this study, MenC- and MenW-specific IgG responses showed a skewing toward the IgG2 subclass, whereas IgG1 skewing was seen for MenY. Since, in general, IgG1 shows better complement binding compared with IgG2 (47), the 
MenY-specific IgG1 skewed response could be considered to be more functional. However, we found the weakest correlation between the total IgG concentrations and rSBA titers for MenY, which does not support the higher functionality of the MenYspecific IgG response in bacterial killing. Therefore, in adults, the exact roles of the IgG subclass responses in antibody functionality remains incompletely understood.

Remarkably, rSBA titers were largely determined by the groupspecific IgM response, especially for MenW and MenY, since depletion of IgG did not significantly reduce the rSBA response, whereas IgM depletion did. IgM is known to be highly effective in complement binding (48) and found to be essential in the functionality of the pneumococcal antibody response (12). We here observed a negative correlation between the IgM response post-meningococcal vaccination and age in middle-aged adults, within a relatively small age range of 15 years. Therefore, we do expect a reduced functional meningococcal antibody response after primary immunization or even infection in the elderly. This expectation is strengthened by previous observations of an inverse correlation between serum IgM as well as IgM + B-cells and age $(12,46,49-51)$. It may be possible to extrapolate to other primary bacterial infections and vaccinations in the elderly. Therefore, we propose to measure IgM responses, next to IgG, following primary bacterial vaccinations in middle-aged and elderly populations. Remarkably, participants possessing very high pre-vaccination IgG concentrations tended to show lower IgM concentrations post-vaccination and did not show a decrease in rSBA titer after IgM depletion. This finding suggests that the antibody functionality is reliant on high levels of IgG during clear booster responses. Since IgG responses may be less affected during the aging process, functional antibody responses develop after additional booster vaccinations during old age. Furthermore, unlike often reported for other pathogens (52), no clear gender differences were observed in the vaccine response in this age group.

In addition, we show high pre-vaccination TT-specific IgG concentrations in the majority of the middle-aged adults, which were highly boosted by the MenACWY-TT vaccination. This finding is different to the study in the Lebanese population, who possessed very low pre-vaccination TT-specific antibody levels that were only minimally boosted by the vaccination (23). This difference in pre-vaccination immunity may be caused by higher frequencies of TT booster vaccinations in the Dutch adults due to traveling or by higher frequencies of childhood TT vaccinations in the Netherlands. Previous surveillance studies also revealed relatively high TT antibodies in Dutch older adults (53). Since the TT carrier protein in this conjugated meningococcal vaccine is added to induce T-cell help in response to the meningococcal polysaccharides in order to induce long-term immunity and memory B-cell formation (54), the amount of T-cell help in our study may be different from the Lebanese population.

This study has important strengths, such as the use of a multivalent vaccine, containing antigens that induced both booster and naive responses in the same participant. This allowed us to compare the immunogenicity of naïve and booster responses within the same group of middle-aged adults. Moreover, the blood sampling at 7 days post-vaccination strengthened our assumption of a general booster response for MenC and more naïve responses for MenW and MenY. In addition, the vaccine immunogenicity was based on an internationally accepted protective threshold in antibody functionality. Although we only measured this antibody functionality in a selection of 100 participants, this selection was representative for the entire cohort, since two independent selections of 50 participants, based on varying IgG responses from low to high concentrations, showed similar rSBA results. Finally, our data add clinically relevant information about the immunogenicity of the MenACWY-TT vaccine in middle-aged adults, which could be used to cease the currently ongoing MenW outbreak or to decrease the vulnerability of the future elderly population for new outbreaks. However, our study was limited in predicting long-term protection due to the short follow-up period. Using the bi-exponential decay model, we estimate that about $40-60 \%$ of our cohort may still be protected 10 years post-vaccination. However, this model needs to be validated by additional sampling of the participants several years post-vaccination. These additional samples are essential to determine the exact beneficial effects of vaccination at middle age for upholding memory immunity in the elderly.

To conclude, primary immunization with a tetravalent meningococcal vaccine, which contains antigens for which no or (very) low pre-vaccination immunity exists, was highly immunogenic in middle-aged adults. One-year post-vaccination protective antibody titers were still found in the vast majority of the participants. Future follow-up studies can determine the long-term protection of this meningococcal vaccination in elderly participants, although long-term protection is predicted in about half of the participants using bi-exponential decay modeling. Moreover, IgM was found essential in the antibody functionality against the new antigens and showed a decrease with advancing age. These findings support the suggestion that immunization against de novo antigens should be implemented before reaching old age. In short, our results imply that enhancing immunological memory by primary vaccination of middle-aged persons is feasible and provides a basis for novel strategies to extend protective immunity until old age.

\section{ETHICS STATEMENT}

This study was carried out in accordance with the recommendations of the Medical Research Ethics Committees United (MEC$\mathrm{U})$ with written informed consent from all subjects. All subjects gave written informed consent in accordance with the Declaration of Helsinki. The protocol was approved by the Medical Research Ethics Committees United (MEC-U) and registered in the Dutch trail register (NTR4636).

\section{AUTHOR CONTRIBUTIONS}

$\mathrm{MH}, \mathrm{AB}, \mathrm{GB}$, and $\mathrm{A}-\mathrm{MB}$ designed the experiments. $\mathrm{MH}$ and LR planned and performed the clinical work. $\mathrm{MH}, \mathrm{LR}, \mathrm{MM}$, 
and IT executed the laboratory experiments. AM performed the bi-exponential modeling. $\mathrm{MH}, \mathrm{AB}, \mathrm{GB}$, and $\mathrm{A}-\mathrm{MB}$ analyzed and interpreted the data. $\mathrm{MH}, \mathrm{AB}, \mathrm{AM}, \mathrm{GB}$, and $\mathrm{A}-\mathrm{MB}$ wrote the manuscript. All authors critically revised the manuscript.

\section{ACKNOWLEDGMENTS}

We thank all the participants of the study and the nurses who performed the vaccinations and blood drawings. Furthermore, we thank Debbie van Rooijen en Mariette van Ravenhorst for sharing their meningococcal laboratory expertise. Finally, we

\section{REFERENCES}

1. United Nations. World Population Ageing. Report. (2015).

2. Michel J-P, Lang PO. Promoting life course vaccination. Rejuvenation Res (2011) 14(1):75-81. doi:10.1089/rej.2010.1078

3. Lang PO, Aspinall R. Immunosenescence and herd immunity: with an ever-increasing aging population do we need to rethink vaccine schedules? Expert Rev Vaccines (2012) 11(2):167-76. doi:10.1586/erv.11.187

4. Rappuoli R, Mandl CW, Black S, De Gregorio E. Vaccines for the twenty-first century society. Nat Rev Immunol (2011) 11(12):865-72. doi:10.1038/nri3085

5. Boraschi D, Aguado MT, Dutel C, Goronzy J, Louis J, Grubeck-Loebenstein B, et al. The gracefully aging immune system. Sci Transl Med (2013) 5(185):s8. doi:10.1126/scitranslmed.3005624

6. Herndler-Brandstetter D, Ishigame H, Flavell RA. How to define biomarkers of human T cell aging and immunocompetence? Front Immunol (2013) 4:136. doi:10.3389/fimmu.2013.00136

7. Siegrist CA, Aspinall R. B-cell responses to vaccination at the extremes of age. Nat Rev Immunol (2009) 9(3):185-94. doi:10.1038/nri2508

8. Arnold CR, Wolf J, Brunner S, Herndler-Brandstetter D, Grubeck-Loebenstein B. Gain and loss of $\mathrm{T}$ cell subsets in old age - age-related reshaping of the T cell repertoire. J Clin Immunol (2011) 31(2):137-46. doi:10.1007/s10875-010-9499-x

9. Frasca D, Diaz A, Romero M, Landin AM, Blomberg BB. Age effects on B cells and humoral immunity in humans. Ageing Res Rev (2011) 10(3):330-5. doi:10.1016/j.arr.2010.08.004

10. Levin MJ. Immune senescence and vaccines to prevent herpes zoster in older persons. Curr Opin Immunol (2012) 24(4):494-500. doi:10.1016/j. coi.2012.06.002

11. Lang PO, Govind S, Michel JP, Aspinall R, Mitchell WA. Immunosenescence: implications for vaccination programmes in adults. Maturitas (2011) 68(4):322-30. doi:10.1016/j.maturitas.2011.01.011

12. Park S, Nahm MH. Older adults have a low capacity to opsonize pneumococci due to low IgM antibody response to pneumococcal vaccinations. Infect Immun (2011) 79(1):314-20. doi:10.1128/IAI.00768-10

13. Lee $\mathrm{H}, \mathrm{Nahm} \mathrm{M,} \mathrm{Kim} \mathrm{K-H.} \mathrm{The} \mathrm{effect} \mathrm{of} \mathrm{age} \mathrm{on} \mathrm{the} \mathrm{response} \mathrm{to} \mathrm{the}$ pneumococcal polysaccharide vaccine. BMC Infect Dis (2010) 10(1):60. doi:10.1186/1471-2334-10-60

14. van Werkhoven CH, Huijts SM, Bolkenbaas M, Grobbee DE, Bonten MJ. The impact of age on the efficacy of 13 -valent pneumococcal conjugate vaccine in elderly. Clin Infect Dis (2015) 61:1835-8. doi:10.1093/cid/civ686

15. Schulz AR, Mälzer JN, Domingo C, Jürchott K, Grützkau A, Babel N, et al. Low thymic activity and dendritic cell numbers are associated with the immune response to primary viral infection in elderly humans. J Immunol (2015) 195(10):4699-711. doi:10.4049/jimmunol.1500598

16. Chen L-H, Chiou G-Y, Chen Y-W, Li H-Y, Chiou S-H. microRNA and aging: a novel modulator in regulating the aging network. Ageing Res Rev (2010) 9:S59-66. doi:10.1016/j.arr.2010.08.002

17. de Voer RM, Mollema L, Schepp RM, de Greeff SC, van Gageldonk PG, de Melker HE, et al. Immunity against Neisseria meningitidis serogroup C in the Dutch population before and after introduction of the meningococcal c conjugate vaccine. PLoS One (2010) 5(8):e12144. doi:10.1371/journal. pone. 0012144 are grateful to Scott McDonald for the English editing of the manuscript.

\section{FUNDING}

This work was funded by the Dutch Ministry of Public Health.

\section{SUPPLEMENTARY MATERIAL}

The Supplementary Material for this article can be found online at http://journal.frontiersin.org/article/10.3389/fimmu.2017.00817/ full\#supplementary-material.

18. Edge C, Waight P, Ribeiro S, Borrow R, Ramsay M, Ladhani S. Clinical diagnoses and outcomes of 4619 hospitalised cases of laboratory-confirmed invasive meningococcal disease in England: linkage analysis of multiple national databases. J Infect (2016) 73(5):427-36. doi:10.1016/j.jinf.2016.07.016

19. Cohn AC, MacNeil JR, Clark TA, Ortega-Sanchez IR, Briere EZ, Meissner HC, et al. Prevention and control of meningococcal disease: recommendations of the Advisory Committee on Immunization Practices (ACIP). MMWR Recomm Rep (2013) 62(RR-2):1-28. doi:10.1086/649209

20. Stoof SP, Rodenburg GD, Knol MJ, Rümke LW, Bovenkerk S, Berbers GA, et al. Disease burden of invasive meningococcal disease in the Netherlands between June 1999 and June 2011; a subjective role for serogroup and clonal complex. Clin Infect Dis (2015) 61:1281-92. doi:10.1093/cid/civ506

21. RIVM. The National Immunisation Programme in the Netherlands-Surveillance and Developments. Ministry of Health, Welfare and Sport (2016).

22. Campbell H, Saliba V, Borrow R, Ramsay M, Ladhani S. Targeted vaccination of teenagers following continued rapid endemic expansion of a single meningococcal group W clone (sequence type 11 clonal complex), United Kingdom 2015. Euro Surveill (2015) 20(28):21188. doi:10.2807/1560-7917. ES2015.20.28.21188

23. Dbaibo G, El-Ayoubi N, Ghanem S, Hajar F, Bianco V, Miller JM, et al Immunogenicity and safety of a quadrivalent meningococcal serogroups A, $\mathrm{C}, \mathrm{W}-135$ and Y tetanus toxoid conjugate vaccine (MenACWY-TT) administered to adults aged 56 Years and older: results of an open-label, randomized, controlled trial. Drugs Aging (2013) 30(5):309-19. doi:10.1007/s40266013-0065-0

24. Ramasamy MN, Clutterbuck EA, Haworth K, Bowman J, Omar O, Thompson AJ, et al. Randomized clinical trial to evaluate the immunogenicity of quadrivalent meningococcal conjugate and polysaccharide vaccines in adults in the United kingdom. Clin Vaccine Immunol (2014) 21(8):1164-8. doi:10.1128/ CVI.00099-14

25. de Voer RM, van der Klis FR, Engels CW, Rijkers GT, Sanders EA, Berbers GA Development of a fluorescent-bead-based multiplex immunoassay to determine immunoglobulin G subclass responses to Neisseria meningitidis serogroup A and C polysaccharides. Clin Vaccine Immunol (2008) 15(8):1188-93. doi:10.1128/CVI.00478-07

26. de Voer RM, Schepp RM, Versteegh FG, van der Klis FR, Berbers GA. Simultaneous detection of Haemophilus influenzae typeb polysaccharide-specific antibodies and Neisseria meningitidis serogroup A, C, Y, and W-135 polysaccharide-specific antibodies in a fluorescent-bead-based multiplex immunoassay. Clin Vaccine Immunol (2009) 16(3):433-6. doi:10.1128/CVI.00364-08

27. van Gageldonk PG, van Schaijk FG, van der Klis FR, Berbers GA. Development and validation of a multiplex immunoassay for the simultaneous determination of serum antibodies to Bordetella pertussis, diphtheria and tetanus. J Immunol Methods (2008) 335(1):79-89. doi:10.1016/j.jim.2008.02.018

28. Lal G, Balmer P, Joseph H, Dawson M, Borrow R. Development and evaluation of a tetraplex flow cytometric assay for quantitation of serum antibodies to Neisseria meningitidis serogroups A, C, Y, and W-135. Clin Vaccine Immunol (2004) 11(2):272-9. doi:10.1128/CDLI.11.2.272-279.2004

29. Galazka A. Tetanus. Module 3. The Immunological Basis for Immunisation Series. Geneva: World Health Organization, Global Programme for Vaccines and Immunization, Expanded Programme on Immunization (1993). 
30. Maslanka SE, Gheesling LL, Libutti DE, Donaldson K, Harakeh HS, Dykes JK, et al. Standardization and a multilaboratory comparison of Neisseria meningitidis serogroup A and C serum bactericidal assays. The Multilaboratory Study Group. Clin Diagn Lab Immunol (1997) 4(2):156-67.

31. Borrow R, Balmer P, Miller E. Meningococcal surrogates of protection-serum bactericidal antibody activity. Vaccine (2005) 23(17):2222-7. doi:10.1016/j. vaccine.2005.01.051

32. Borrow R, Andrews N, Goldblatt D, Miller E. Serological basis for use of meningococcal serogroup $\mathrm{C}$ conjugate vaccines in the United Kingdom: reevaluation of correlates of protection. Infect Immun (2001) 69(3):1568-73. doi:10.1128/IAI.69.3.1568-1573.2001

33. Teunis P, van Eijkeren J, de Graaf W, Marinović AB, Kretzschmar M. Linking the seroresponse to infection to within-host heterogeneity in antibody production. Epidemics (2016) 16:33-9. doi:10.1016/j.epidem.2016.04.001

34. van Ravenhorst MB, Marinovic AB, van der Klis FR, van Rooijen DM, van Maurik M, Stoof SP, et al. Long-term persistence of protective antibodies in Dutch adolescents following a meningococcal serogroup $\mathrm{C}$ tetanus booster vaccination. Vaccine (2016) 34(50):6309-15. doi:10.1016/j.vaccine.2016.10.049

35. Slifka MK, Antia R, Whitmire JK, Ahmed R. Humoral immunity due to long-lived plasma cells. Immunity (1998) 8(3):363-72. doi:10.1016/ S1074-7613(00)80541-5

36. Jackson LA, Gurtman A, van Cleeff M, Jansen KU, Jayawardene D, Devlin C, et al. Immunogenicity and safety of a 13 -valent pneumococcal conjugate vaccine compared to a 23-valent pneumococcal polysaccharide vaccine in pneumococcal vaccine-naive adults. Vaccine (2013) 31(35):3577-84. doi:10.1016/ j.vaccine.2013.04.085

37. Bryant K, Frenck R, Gurtman A, Rubino J, Treanor J, Thompson A, et al. Immunogenicity and safety of a 13 -valent pneumococcal conjugate vaccine in adults 18-49 years of age, naive to 23-valent pneumococcal polysaccharide vaccine. Vaccine (2015) 33(43):5854-60. doi:10.1016/j.vaccine.2015.08.080

38. Siegrist C-A. Vaccine immunology. In: Plotkin S, Orenstein W, Offit P, editors. Vaccines. 5th ed. Philadelphia, PA: Saunders Elsevier (2008). p. 17-36.

39. De Voer RM, Van der Klis FR, Engels CW, Schepp RM, Van de Kassteele J, Sanders EA, et al. Kinetics of antibody responses after primary immunization with meningococcal serogroup C conjugate vaccine or secondary immunization with either conjugate or polysaccharide vaccine in adults. Vaccine (2009) 27(50):6974-82. doi:10.1016/j.vaccine.2009.09.082

40. Bijlsma MW, Brouwer MC, Spanjaard L, van de Beek D, van der Ende A. A decade of herd protection after introduction of meningococcal serogroup C conjugate vaccination. Clin Infect Dis (2014) 59(9):1216-21. doi:10.1093/cid/ciu601

41. Crotty S, Ahmed R. Immunological memory in humans. Semin Immunol (2004) 16:197-203. doi:10.1016/j.smim.2004.02.008

42. Perrett KP, Jin C, Clutterbuck E, John TM, Winter AP, Kibwana E, et al. B cell memory to a serogroup $\mathrm{C}$ meningococcal conjugate vaccine in childhood and response to booster: little association with serum IgG antibody. J Immunol (2012) 189(5):2673-81. doi:10.4049/jimmunol.1200451

43. Findlow H, Southern J, Mabey L, Balmer P, Heyderman RS, Auckland C, et al. Immunoglobulin $\mathrm{G}$ subclass response to a meningococcal quadrivalent polysaccharide-diphtheria toxoid conjugate vaccine. Clin Vaccine Immunol (2006) 13(4):507-10. doi:10.1128/CVI.13.4.507-510.2006

44. Bredius R, Driedijk P, Schouten M, Weening R, Out T. Complement activation by polyclonal immunoglobulin G1 and G2 antibodies against Staphylococcus aureus, Haemophilus influenzae type b, and tetanus toxoid. Infect Immun (1992) 60(11):4838-47.

45. Soininen A, Seppälä I, Nieminen T, Eskola J, Käyhty H. IgG subclass distribution of antibodies after vaccination of adults with pneumococcal conjugate vaccines. Vaccine (1999) 17(15):1889-97. doi:10.1016/S0264-410X(98)00475-7

46. Wu YC, Kipling D, Dunn-Walters DK. Age-related changes in human peripheral blood IGH repertoire following vaccination. Front Immunol (2012) 3:193. doi:10.3389/fimmu.2012.00193

47. Vidarsson G, Dekkers G, Rispens T. IgG subclasses and allotypes: from structure to effector functions. Front Immunol (2014) 5:520. doi:10.3389/ fimmu.2014.00520

48. Shyur SD, Raff HV, Bohnsack JF, Kelsey DK, Hill HR. Comparison of the opsonic and complement triggering activity of human monoclonal IgG1 and IgM antibody against group B streptococci. J Immunol (1992) 148(6):1879-84.

49. Martin V, Wu YC, Kipling D, Dunn-Walters DK. Age-related aspects of human IgM+ B cell heterogeneity. Ann N Y Acad Sci (2015) 1362(1):153-63. doi:10.1111/nyas.12823

50. Shi Y, Yamazaki T, Okubo Y, Uehara Y, Sugane K, Agematsu K. Regulation of aged humoral immune defense against pneumococcal bacteria by IgM memory B cell. J Immunol (2005) 175(5):3262-7. doi:10.4049/jimmunol.175.5.3262

51. Dunn-Walters D. The ageing human B cell repertoire: a failure of selection? Clin Exp Immunol (2016) 183(1):50-6. doi:10.1111/cei.12700

52. Klein SL, Marriott I, Fish EN. Sex-based differences in immune function and responses to vaccination. Trans R Soc Trop Med Hyg (2015) 109(1):9-15. doi: $10.1093 /$ trstmh/tru167

53. Steens A, Mollema L, Berbers G, Van Gageldonk P, Van der Klis F, De Melker H. High tetanus antitoxin antibody concentrations in the Netherlands: a seroepidemiological study. Vaccine (2010) 28(49):7803-9. doi:10.1016/j.vaccine. 2010.09.036

54. Pollard AJ, Perrett KP, Beverley PC. Maintaining protection against invasive bacteria with protein-polysaccharide conjugate vaccines. Nat Rev Immunol (2009) 9(3):213-20. doi:10.1038/nri2494

Conflict of Interest Statement: MH, AM, LR, MM, IT, GB, and A-MB declare no conflict of interest. AB is a consultant for Grunenthal Gmbh (Germany).

Copyright (C) 2017 van der Heiden, Boots, Bonacic Marinovic, de Rond, van Maurik, Tcherniaeva, Berbers and Buisman. This is an open-access article distributed under the terms of the Creative Commons Attribution License (CC BY). The use, distribution or reproduction in other forums is permitted, provided the original author(s) or licensor are credited and that the original publication in this journal is cited, in accordance with accepted academic practice. No use, distribution or reproduction is permitted which does not comply with these terms. 